\title{
Insulin-induced Lipohypertrophy: Report of a Case with Histopathology
}

\author{
JUNJI FUJIKURA, MUNEYA FUJIMOTO, SHINTARO YASUE, MiCHIO NOGUCHI, HIROAKI MASUZAKI, \\ KIMINORI HOSODA, TAKAO TACHIBANA*, HAJIME SUGIHARA** AND KAZUWA NAKAO \\ Department of Medicine and Clinical Science, Division of Endocrinology and Metabolism, Kyoto University Graduate School of \\ Medicine, Kyoto 606-8507, Japan \\ *Department of Dermatology, Tenri Yorozu Hospital, Nara 632-8552, Japan \\ **Department of Pathology, International University of Health and Welfare, Okawa 831-0004, Japan
}

\begin{abstract}
An 82-year-old woman with type 2 diabetes had been treated with recombinant human insulin for 16 years. She developed large swellings in both sides of her lower abdomen. The masses were soft, painless, and located around her insulin injection sites. Based on the history and clinical features, a diagnosis of insulin-induced lipohypertrophy was made. Total resection revealed that the lesions were composed entirely of fatty tissue. Microscopic examination showed nests of mature adipocytes expanding toward the dermal reticular layer. The hypertrophic adipocytes were twice as large as those from normal subcutaneous areas and contained numerous small lipid droplets. Electron microscopic analysis also revealed a minor population of small adipocytes, suggesting active differentiation or proliferation. Thus, the possible in vivo effects of insulin on adipocytes were clearly observed in this case of insulin-induced lipohypertrophy. To our knowledge, this is the first report of insulin-induced lipohypertrophy with detailed histological examinations.
\end{abstract}

Key words: Insulin-induced lipohypertrophy, Adipocytes, Scanning electron microscopy

(Endocrine Journal 52: 623-628, 2005)

THE incidence and prevalence of diabetes mellitus is increasing at an alarming rate [1]. Good glycemic control reduces the risk of complications of diabetes. Secondary failure of oral hypoglycemic treatment is common in patients with type 2 diabetes, and thus insulin treatment is often needed to improve glycemic control. Indeed, in the UK prospective diabetes study, with over 10 years of observation, $38 \%$ of patients needed insulin treatment to reduce fasting plasma glucose concentrations to $<6 \mathrm{mmol} / \mathrm{l}$ [2]. Furthermore, modern therapy involves greater and earlier use of intensive insulin regimens to achieve better control of blood glucose levels and reduce the long-term risks of diabetes [3].

Insulin therapy is associated with skin related com-

Received: June 16, 2005

Accepted: August 4, 2005

Correspondence to: Dr. Junji FUJIKURA, 54 Shogoin Kawaracho, Sakyo-ku, Kyoto, Kyoto 606-8507, Japan plications, such as lipoatrophy, lipohypertrophy, edema, or allergy [4]. Among them, lipohypertrophy is the most common cutaneous complication, characterized by a tumor-like swelling of fatty tissue around subcutaneous insulin injection sites [5-7]. The purpose of this case report is to present a detailed histological analysis of insulin-induced lipohypertrophy in a patient with type 2 diabetes mellitus.

\section{Case Report}

An 82-year-old woman with type 2 diabetes had been treated with insulin for 16 years. Initially, she was treated by her private physician; however, in December 2003, her physician noted soft painless swellings on her abdomen and she was admitted to our hospital. On admission, she was $147 \mathrm{~cm}$ tall and weighed $46 \mathrm{~kg}$ (BMI $21.3 \mathrm{~kg} / \mathrm{m}^{2}$ ). Her blood pressure was $121 / 68 \mathrm{mmHg}$ and pulse rate was 66 beats per 
minute. She was taking 6 units of regular insulin before meals and 6 units of NPH insulin at bedtime. Her diabetic control was poor (HbA1c 8.3\%) and she displayed mild diabetic neuropathy. She had developed two large masses, one at each side of her lower abdomen (Fig. 1). Both masses were soft, rounded, and movable, and were about $10 \mathrm{~cm}$ in diameter. There were scars on the surface of the skin, areas that represented her current insulin injection sites (arrows in Fig. 1). No other clinical abnormalities were present. Hematological and biochemical tests were unremarkable (Table 1). Based on the above
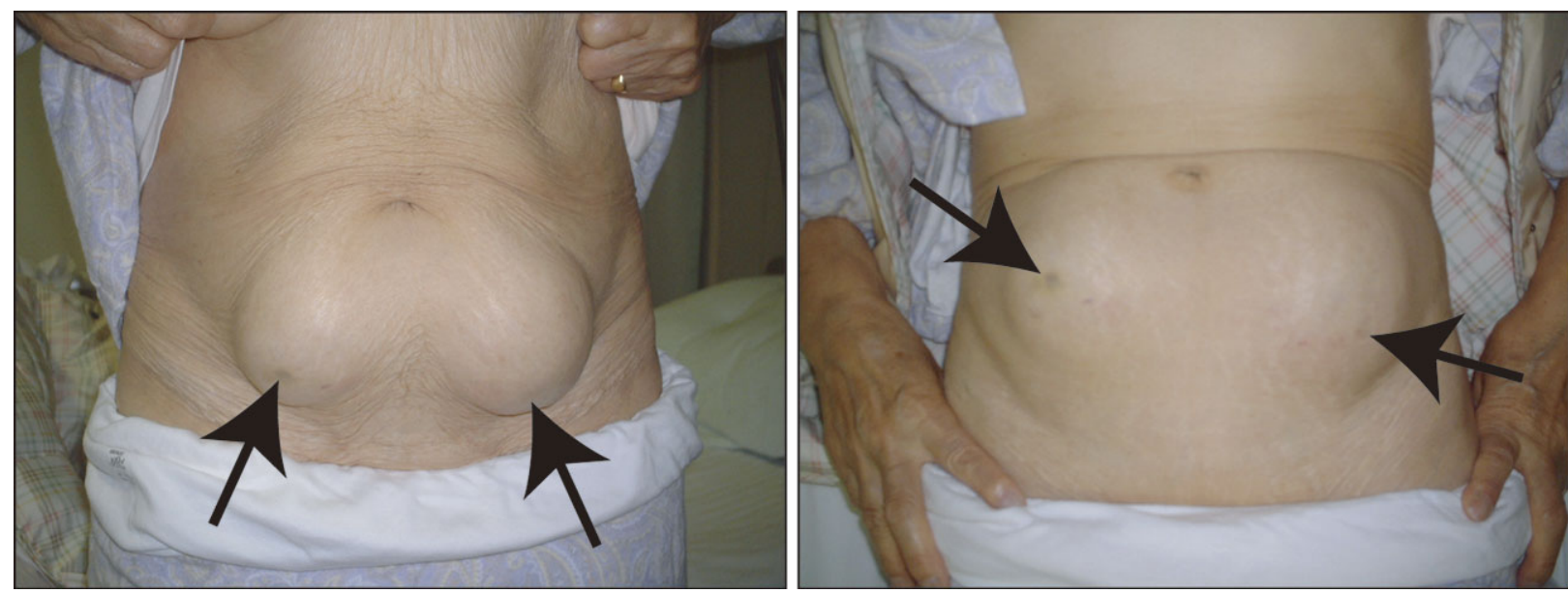

Fig. 1. Large movable abdominal masses. Pictures were taken in two body positions, standing (left) and spine (right). There are scars at the sites of insulin injections (arrows).

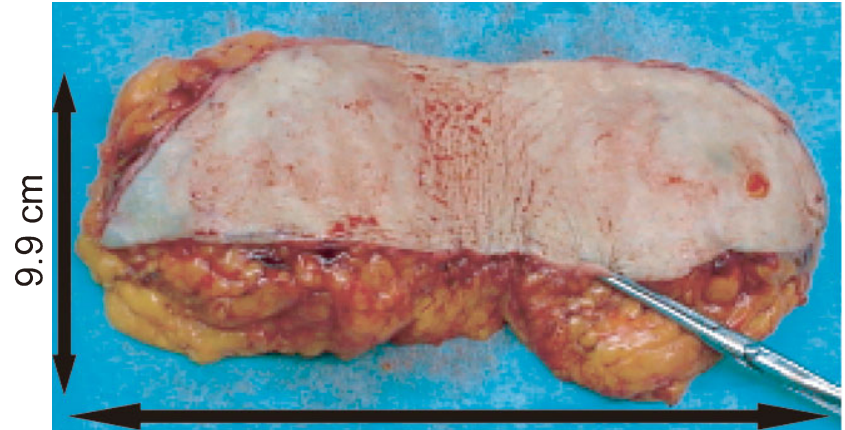

$24.2 \mathrm{~cm}$

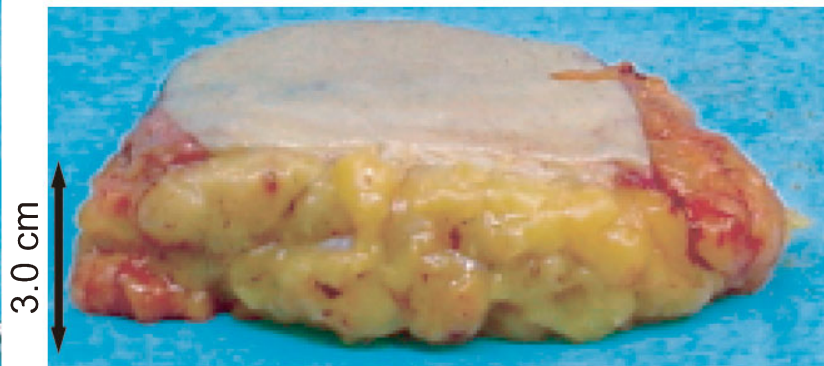

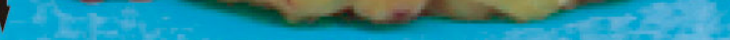

Fig. 2. Surgically resected specimen. Outside view (left) of the whole specimen and a cross-sectional view (right) of the specimen. The two masses were composed of yellowish fatty tissues and were not encapsulated by fibrous tissues.

Table 1. Laboratory data

\begin{tabular}{|c|c|c|c|c|c|}
\hline White blood cell & $6100 / \mu \mathrm{l}$ & $\gamma$-glutamyltrnaspeptidase & $13 \mathrm{IU} / \mathrm{l}$ & $\mathrm{HbAlc}$ & \\
\hline Red blood cell & $434 \times 10^{4} / \mu \mathrm{l}$ & Total cholesterol & $213 \mathrm{mg} / \mathrm{dl}$ & before surgery & $8.3 \%$ \\
\hline Hemoglobin & $11.8 \mathrm{~g} / \mathrm{dl}$ & High density lipoprotein & $50 \mathrm{mg} / \mathrm{dl}$ & after surgery & $7.1 \%$ \\
\hline Hematocrit & $37 \%$ & Triglyceride & $60 \mathrm{mg} / \mathrm{dl}$ & Leptin & \\
\hline Platelet & $19.4 \times 10^{4} / \mathrm{ml}$ & Blood urea nitrogen & $21 \mathrm{mg} / \mathrm{dl}$ & before surgery & $2.8 \mathrm{ng} / \mathrm{ml}$ \\
\hline CRP & $0.3 \mathrm{mg} / \mathrm{dl}$ & Creatinine & $0.7 \mathrm{mg} / \mathrm{dl}$ & after surgery & $4.6 \mathrm{ng} / \mathrm{ml}$ \\
\hline Aspartate aminotransferase & $25 \mathrm{IU} / 1$ & Uric acid & $4.5 \mathrm{mg} / \mathrm{dl}$ & Adioponectin & \\
\hline Alanine aminotransferase & $15 \mathrm{IU} / 1$ & Fasting plasma glucose & $8.3 \mathrm{mmol} / \mathrm{l}$ & before surgery & $25.8 \mathrm{mg} / \mathrm{ml}$ \\
\hline Lactate dehydrogenase & $231 \mathrm{IU} / 1$ & GAD antibody & negative & after surgery & $31.1 \mathrm{mg} / \mathrm{ml}$ \\
\hline Alkaline phosphatase & $218 \mathrm{IU} / 1$ & Anti-Insulin antibody & $34.2 \%$ & & \\
\hline
\end{tabular}


findings, a clinical diagnosis of insulin-induced lipohypertrophy was made. She was instructed to avoid the abdomen as a site for injections and to use a multiple rotation method. Her glycemic control improved after changing insulin injection sites. However, the hypertrophy was not resolved after a month. Surgical excision for cosmetic purposes was performed under local anesthesia. The en bloc-resected surgical specimen was $24.2 \times 9.9 \times 3.0 \mathrm{~cm}$, and weighed $405 \mathrm{~g}$ (Fig. 2). The lesions were composed entirely of a yellowish material and were not encapsulated by fibrous tissues. The gross findings were compatible with benign lipohypertrophy. Although the tumors were large, her serum leptin and adiponectin levels were not significantly changed after surgery (Table 1). Light and electron microscopic examinations were carried out on the lipohypertrophic tissues and surrounding normal adipose tissues. Hematoxylin and eosin (HE) staining of sections from lipohypertrophic tissues showed excess mature adipocytes in the dermal reticular layer (Fig. 3A). We observed a significant increase in the size of adipocytes in the lipohypertrophic area (diameters 100 to $200 \mu \mathrm{m}$, Fig. 3B), compared with the surrounding normal areas (diameters 70 to $90 \mu \mathrm{m}$, Fig. $3 \mathrm{C}$ ). This increase in the volume of adipocytes was confirmed with scanning electron microscopy (SEM) (Fig. 4). Approximately $10 \%$ of the adipocytes in the lipohypertrophic area contained numerous lipid droplets at their periphery, as seen by light microscopy (arrow in Fig. 5A) and SEM (Figs. 5B and 5C), showing stimulated lipogenesis. Some heterogeneity in the size of adipocytes was observed in the lipohypertrophic area (Figs. 4 and 6). A few adipocytes, surrounded by hypertrophic adipocytes, were as small as $20 \mu \mathrm{m}$ in diameter (arrowheads in Fig. 6).
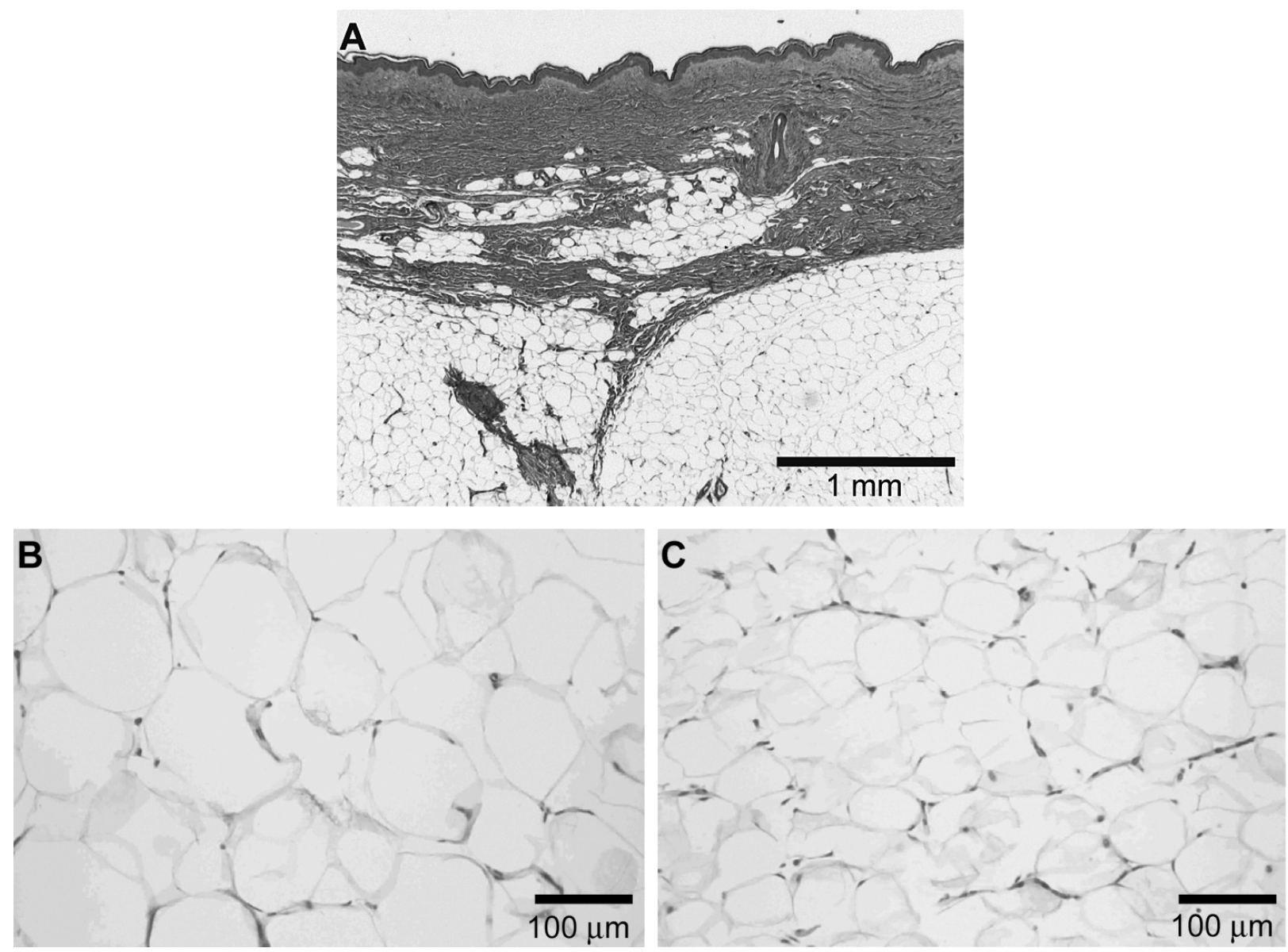

Fig. 3. Fat infiltration in the dermis (A) and hypertrophic adipocytes (B). Hematoxylin-eosin (HE) stained sections from the insulininduced lipohypertrophy (A, magnification: $\times 40$; B, magnification: $\times 200)$ and the adjacent normal subcutaneous adipose tissue $(\mathrm{C}$, magnification: $\times 200)$. 

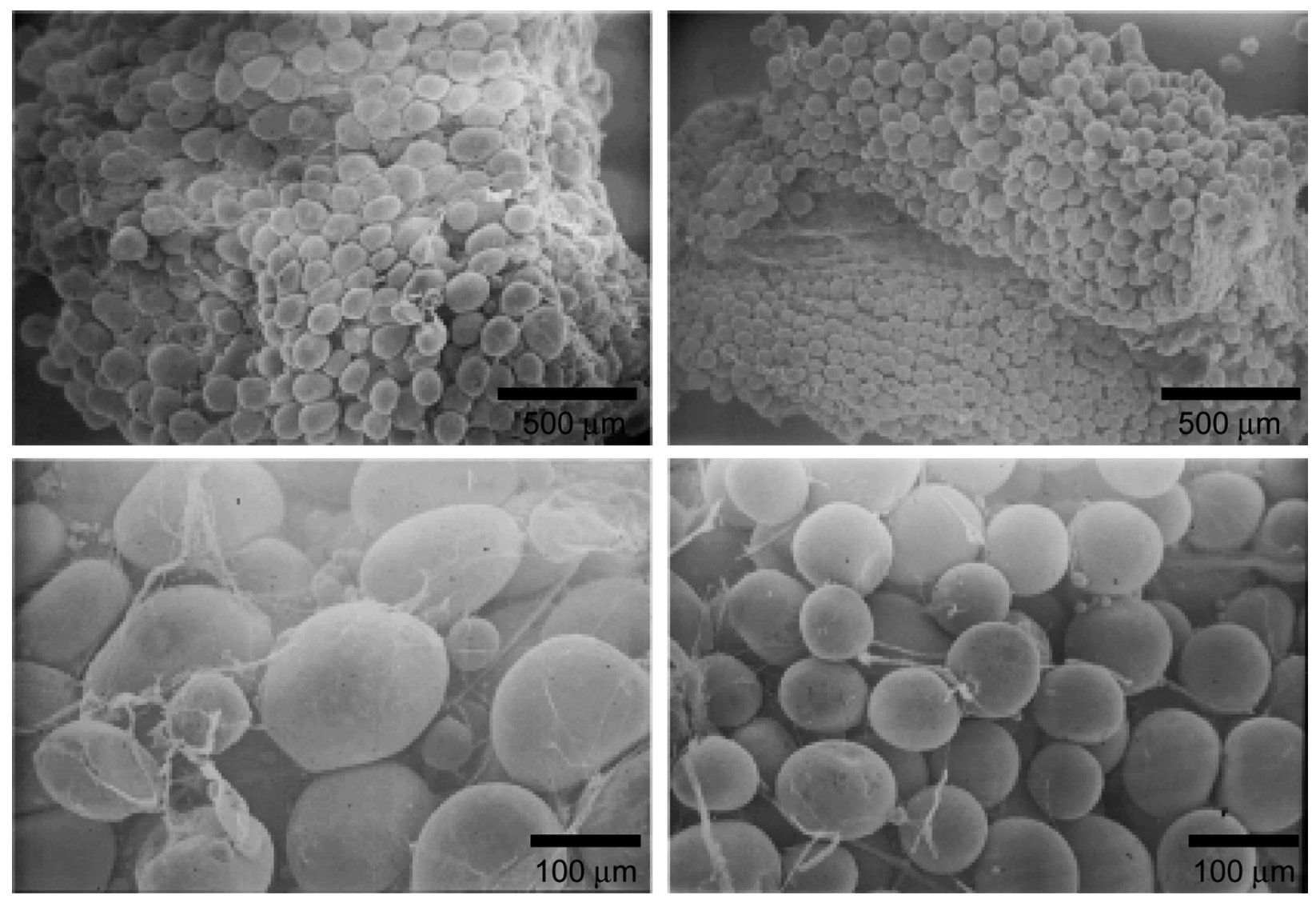

Fig. 4. Hypertrophic adipocytes. Scanning electron microscopy of the insulin-induced lipohypertrophy (left) and adjacent normal subcutaneous adipose tissue (right) at magnifications of $\times 50$ (upper) and $\times 100$ (lower).

\section{Discussion}

Lipodystrophy is a potential clinical adverse effect associated with intensive insulin therapy.

Insulin-induced lipoatrophy is the loss of subcutaneous fat at the site of insulin injection. Although this complication occurred in $25 \%-55 \%$ of patients before the development of highly purified recombinant human insulin, it is now quite rare [8]. The pathological mechanisms therefore may have involved an immunemediated inflammatory reaction to impurities in the insulin products [9].

The prevalence of insulin-induced lipohypertrophy is reported to be $29 \%$ in patients with type 1 diabetes and $4 \%$ in patients with type 2 diabetes [5]. Our patient preferentially injected at the same sites because of their relative anesthesia. The total dose of administered insulin was estimated to be as much as 103,800 units. Furthermore, she believed that all diabetics who used insulin inevitably had such swellings. Lipohyper- trophic nodules have decreased vascularity, which delays insulin absorption [10]. Recent reports show that lipohypertrophy is a very frequent problem in diabetic patients associated with poor glycemic control $[6,11]$. In this patient, there was good improvement in her glycemic control (HbAlc 7.1\%) after changing insulin injection sites.

The pathophysiology of insulin-induced lipohypertrophy is generally thought to be the result of the lipogenic effects of insulin. Our histological examination clearly shows the consequences of the lipogenic actions of insulin on adipocytes (Figs. 3-5). However, although the enlarged adipocytes are impressive (Figs. 3 and 4), the large volume of lipohypertrophic mass is only partially explained by the levels of cellular hypertrophy. In human obesity, when body weight exceeds $170 \%$ of ideal, a maximum adipocyte size of the twice normal is achieved and hyperplasia becomes increasingly manifest with greater severity [12]. It is well known that insulin stimulates proliferation and dif- 

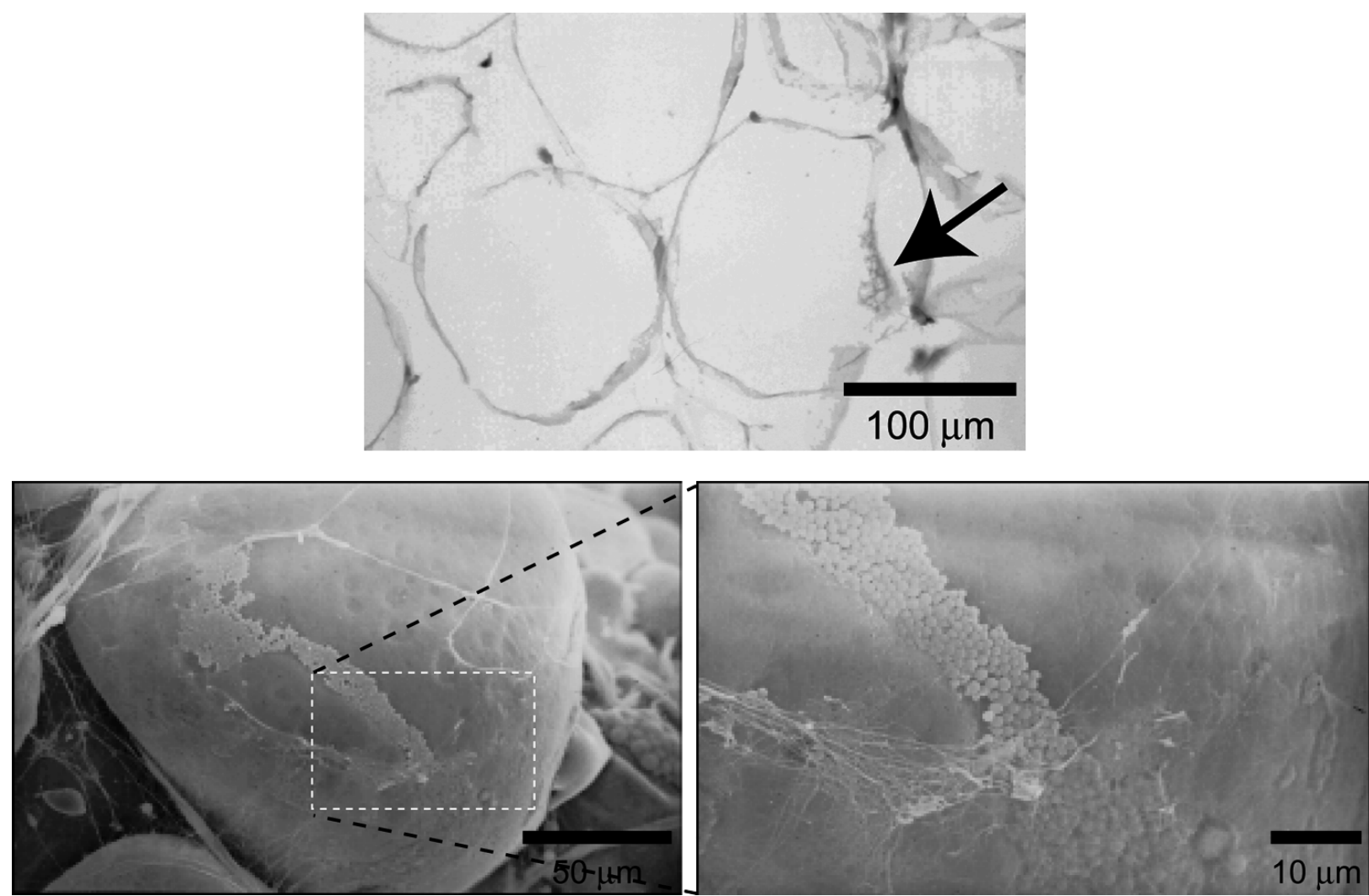

Fig. 5. Numerous small lipid droplets at the periphery of hypertrophic adipocytes. HE staining (upper, magnification: $\times 400$ ) and SEM (lower left; magnification: $\times 500$; lower right, magnification: $\times 1500$ ) of the insulin-induced lipohypertrophy. The arrow in the upper picture shows subcellular lipid droplets. The lower SEM images show exposed lipid droplets underneath the plasma membrane.

ferentiation of preadipocytes $[13,14]$. The possible asymmetric cell division of mature human adipocytes has also been reported $[15,16]$. Small adipocytes seen in the lipohypertrophic area (arrowheads in Fig. 6) would be newly formed adipocytes, arising either by differentiation or by proliferation, in the course of maturation. Taken together, lipohypertrophy is therefore assumed to be the result of maximum hypertrophy and accompanying hyperplasia stimulated by insulin.

The treatment of insulin-induced lipohypertrophy is to change injection sites in the hope that regression will occur. However, when the excessive fat tissue does not decrease, an invasive surgical procedure is necessary. Further analyses of cases would reveal the pathological mechanisms of insulin-induced lipohypertrophy and provide theoretical foundations for prevention and less

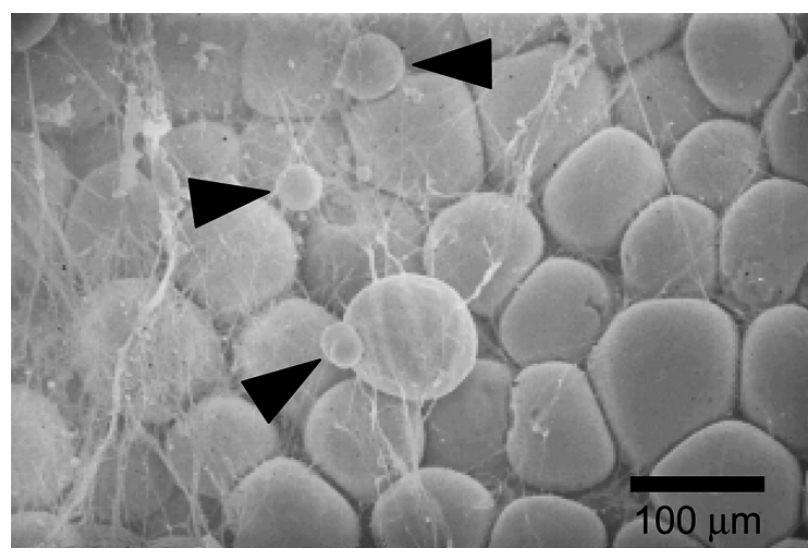

Fig. 6. Heterogeneous size of adipocytes in the insulin-induced lipohypertrophy. Arrowheads in the SEM (magnification: $\times 200$ ) image indicate small adipocytes. invasive treatments. 


\section{References}

1. Mokdad AH, Ford ES, Bowman BA, Nelson DE, Engelgau MM, Vinicor F, Marks JS (2001) The continuing increase of diabetes in the US. Diabetes Care 24: 412.

2. UK Prospective Diabetes Study (UKPDS) Group (1998) Intensive blood-glucose control with sulphonylureas or insulin compared with conventional treatment and risk of complications in patients with type 2 diabetes (UKPDS 33). Lancet 352: 837-853.

3. The Diabetes Control and Complications Trial/Epidemiology of Diabetes Interventions and Complications Research Group (2000) Retinopathy and nephropathy in patients with type 1 diabetes four years after a trial of intensive therapy. N Engl J Med 342: 381-389.

4. Richardson T, Kerr D (2003) Skin-related complications of insulin therapy: epidemiology and emerging management strategies. Am J Clin Dermatol 4: 661667.

5. Schiazza L, Occella C, Bleidl D, Rampini E (1990) Insulin lipohypertrophy. $J$ Am Acad Dermatol 22: 148-149.

6. Hauner H, Stockamp B, Haastert B (1996) Prevalence of lipohypertrophy in insulin-treated diabetic patients and predisposing factors. Exp Clin Endocrinol 104: 106-110.

7. Kordonouri O, Lauterborn R, Deiss D (2002) Lipohypertrophy in young patients with type 1 diabetes. Diabetes Care 25: 634.
8. $\mathrm{Mu}$ L, Goldman JM (2000) Human recombinant DNA insulin-induced lipoatrophy in a patient with type 2 diabetes mellitus. Endocr Pract 6: 151-152.

9. Reeves WG, Allen BR, Tattersall RB (1980) Insulininduced lipoatrophy: evidence for an immune pathogenesis. $\mathrm{Br}$ Med J 280: 1500-1503.

10. Young RJ, Hannan WJ, Frier BM, Steel JM, Duncan LJ (1984) Diabetic lipohypertrophy delays insulin absorption. Diabetes Care 7: 479-480.

11. Chowdhury TA, Escudier V (2003) Poor glycaemic control caused by insulin induced lipohypertrophy. $\mathrm{Br}$ Med J 327: 383-384.

12. Hirsch J, Batchelor B (1976) Adipose tissue cellularity in human obesity. Clin Endocrinol Metab 5: 299-311.

13. Russell TR, Ho R (1976) Conversion of 3 T3 fibroblasts into adipose cells: triggering of differentiation by prostaglandin F2alpha and 1-methyl-3-isobutyl xanthine. Proc Natl Acad Sci USA 73: 4516-4520.

14. Geloen A, Collet AJ, Guay G, Bukowiecki LJ (1989) Insulin stimulates in vivo cell proliferation in white adipose tissue. Am J Physiol 256: C190-C196.

15. Sugihara H, Yonemitsu N, Miyabara S, Toda S (1987) Proliferation of unilocular fat cells in the primary culture. J Lipid Res 28: 1038-1045.

16. Zhang HH, Kumar S, Barnett AH, Eggo MC (2000) Ceiling culture of mature human adipocytes: use in studies of adipocyte functions. J Endocrinol 164: 119128. 